\title{
Morphometric Analysis of Implant-Related Anatomy in Caucasian Skulls
}

\author{
Rodrigo F. Neiva, ${ }^{*}$ Ricardo Gapski, ${ }^{\dagger}$ and Hom-Lay Wang*
}

Background: Sequelae related to implant placement/advanced bone grafting procedures are a result of injury to surrounding anatomic structures. Damage may not necessarily lead to implant failure; however, it is the most common cause of legal action against the practitioner. This study aimed to describe morphological aspects and variations of the anatomy directly related to implant treatment.

Methods: Morphometric analyses were performed in 22 Caucasian skulls. Measurements of the mental foramen (MF) included height (MF-H), width (MF-W), and location in relation to other known anatomical landmarks. Presence or absence of anterior loops (AL) of the inferior alveolar nerve (IAN) was determined, and the mesial extent of the loop was measured. Additional measurements included height $(\mathrm{G}-\mathrm{H})$, width $(\mathrm{G}-\mathrm{W})$, thickness $(\mathrm{G}-\mathrm{T})$, and volume $(\mathrm{G}-\mathrm{V})$ of monocortical onlay grafts harvested from the mandibular symphysis area, and thickness of the lateral wall (T-LW) of the maxillary sinus. The independent samples $t$ test, and a two-tailed $t$ test with equal variance were utilized to determine statistical significance to a level of $P<0.05$. Multiple regression analyses were performed to determine if each one of these measurements was affected by age and gender.

Results: The most common location of the MF in relation to teeth was found to be below the apices of mandibular premolars. The mean MF-H was $3.47 \pm 0.71 \mathrm{~mm}$ and the mean MF-W was $3.59 \pm$ $0.8 \mathrm{~mm}$. The mean distance from the $M F$ to other anatomical landmarks were: $M F-C E J=15.52 \pm 2.37 \mathrm{~mm}, M F$ to the most apical portion of the lower cortex of the mandible $=12.0 \pm 1.67 \mathrm{~mm}, \mathrm{MF}$ to the midline $=27.61 \pm 2.29 \mathrm{~mm}$, and $M F-M F=55.23 \pm 5.34 \mathrm{~mm}$. A high prevalence of AL was found (88\%); symmetric occurrence was a common finding (76.2\%), with a mean length of $4.13 \pm$ $2.04 \mathrm{~mm}$. The mean size of symphyseal grafts was: $\mathrm{G}-\mathrm{H}=9.45 \pm$ $1.08 \mathrm{~mm}, \mathrm{G}-\mathrm{W}=14.5 \pm 3.0 \mathrm{~mm}$, and G-T $=6.15 \pm 1.04 \mathrm{~mm}$, with an average G-V of $857.55 \pm 283.97 \mathrm{~mm}^{3}$ (range: 352 to $1,200 \mathrm{~mm}^{3}$ ). The mean T-LW of the maxillary sinus was $0.91 \pm 0.43 \mathrm{~mm}$.

Conclusion: Implant-related anatomy must be carefully evaluated before treatment due to considerable variations among individuals, in order to prevent injury to surrounding anatomical structures and possible damage. J Periodontol 2004;75:1061-1067.

\section{KEY WORDS}

Dental implantation/adverse effects; dental implants/adverse effects; foramen, mental; grafts, bone; jaw/anatomy and histology; jaw/injuries; maxillary sinus augmentation; mandibular symphysis.

\footnotetext{
* Department of Periodontics/Prevention/Geriatrics, School of Dentistry, University of Michigan, Ann Arbor, MI.

$\dagger$ Currently, Department of Periodontics, School of Dentistry, University of Missouri, Kansas City, MO; previously, Department of Periodontics/Prevention/Geriatrics, School of Dentistry, University of Michigan.
}

Whe replacement of missing teeth with endosseous dental implants has become an important part of dentistry. Over the last 3 decades, research has supported the success of dental implants as a viable and predictable replacement for partial and complete edentulism. Although techniques and materials have been developed which are capable of a high success rate, complications may occur, either during or after implant placement. Special attention must be paid in order to avoid complications at the time of implant placement. While complications that occur after surgery may lead only to implant failure, complication at the time of implant placement may lead to either transient or permanent sequelae caused by violation of anatomic structures resulting in body injury. Sequelae related to implant placement may not necessarily lead to implant failure. However, they are the most common cause of law suits against the practitioner. ${ }^{1}$

The aim of this study was to evaluate the anatomy most commonly associated with implant dentistry and advanced bone grafting procedures, such as symphysis onlay grafts and sinus lifts, and to provide dimensional measurements that could aid the clinician in overall implant treatment planning.

\section{MATERIALS AND METHODS}

Morphometric analyses were performed following crestal and/or intrasulcular incisions and full-thickness mucoperiosteal flap elevation in 22 Caucasian skulls obtained from the Department of Anatomical Sciences, School of Medicine, University 
of Michigan. Mean age of the specimens was $79.1 \pm 11.4$ years $(40.9 \%$ males, 59.1\% females). Following flap elevation, the anatomic structures were identified and the measurements described below were taken.

\section{Mental Foramen}

Size. Height and width, defined as the longest vertical and horizontal measurements identified, of each mental foramen (MF) were measured. Height was measured from the most coronal aspect to the most apical aspect of the MF (MF-H). Width was measured from the most distal aspect to the most mesial aspect of the MF (MF-W). Measurements were taken using a standard

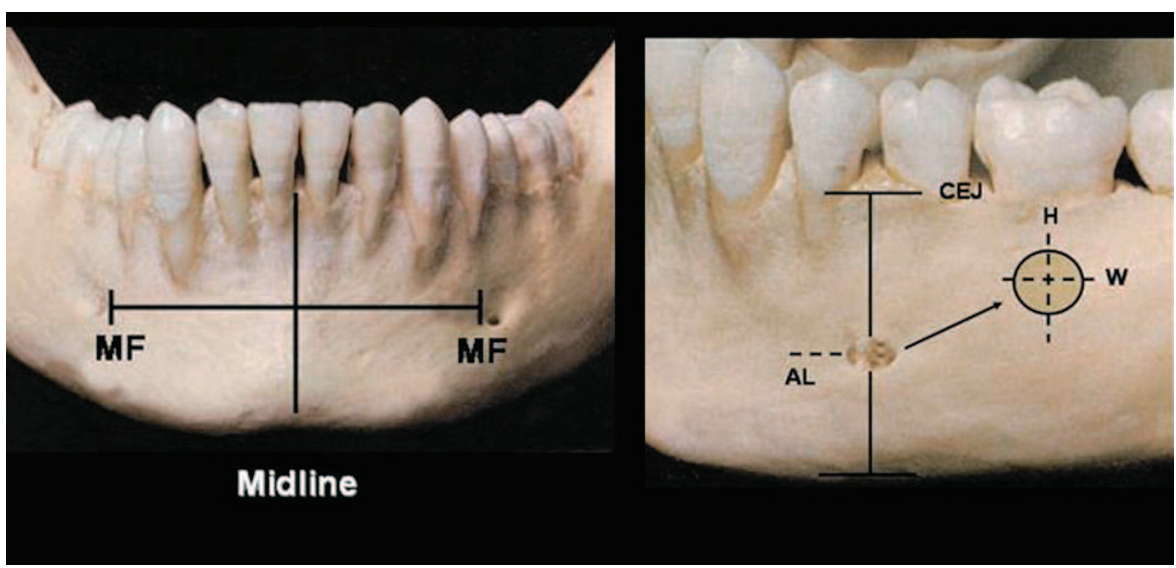

Figure I.

Measurements of height and width of the MF, and also location in relation to surrounding anatomical structures. UNC probe. ${ }^{\dagger}$

Location. The location of each MF was determined by its relation to surrounding anatomical landmarks such as neighboring teeth; most apical portion of the buccal cemento-enamel junction (MF-CEJ) of the tooth immediately superior to the MF; most apical aspect of each $M F$ to the most apical portion of the lower cortex of the mandible immediately inferior to the MF (MF-LC); most mesial aspect of each $M F$ to the midline of the symphysis (MF-MD); and most mesial aspect of each MF in relation to the contralateral MF (MF-MF) (Fig. 1).

\section{Anterior Loops}

The presence or absence of anterior loops (AL) of the inferior alveolar nerve (IAN) was determined by probing the mesial cortical wall of each MF. A positive reading determined the presence of AL. When an AL was detected, the length of the anterior extension of this loop was measured using a standard UNC probe. Measurements were recorded to the nearest millimeter.

\section{Symphysis Onlay Grafts}

Onlay block grafts were harvested from the symphysis area respecting the $5 \times 5 \times 5$ rule described by Hunt and Jovanovic. ${ }^{2}$ These numbers represent safety limits for harvesting grafts from the symphysis area and correspond to $5 \mathrm{~mm}$ from the mesial aspect of each $\mathrm{MF}, 5 \mathrm{~mm}$ from the apices of the lower anterior teeth, and $5 \mathrm{~mm}$ from the apical cortex of the mandible. Two blocks were harvested from each symphysis, respecting a minimum $3 \mathrm{~mm}$ distance from each osteotomy at the midline. The depth of the osteotomy was determined by the immediate penetration into intramarrow spaces, noted by a sudden drop of the bur (Fig. 2).

Following block removal, the thickness, height, and length of the block were recorded. Using these measurements, the volume of each block was calculated. Each block was also examined for its composition.

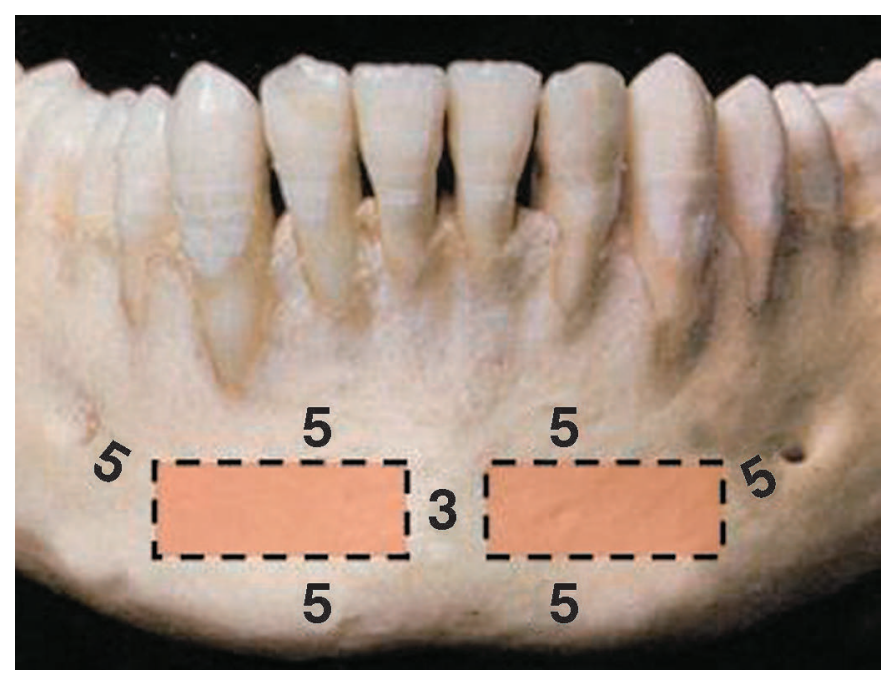

Figure 2.

Onlay grafts allowed a $5 \mathrm{~mm}$ distance from each MF, $5 \mathrm{~mm}$ from the lower cortex, and $5 \mathrm{~mm}$ from the apices of the teeth. An additional $3 \mathrm{~mm}$ distance was allowed from each block.

Percentages were given to cortical and cancellous bone present in the block following cross-sectioning.

\section{Maxillary Sinuses}

Osteotomies were prepared for maxillary sinus grafting using the lateral approach as described by Tatum. ${ }^{3}$ Drilling was performed using a $6 \mathrm{~mm}$ round diamond bur in order to create a window that could provide access for membrane elevation and subsequent grafting. The osteotomy was discontinued as soon as the Schneiderean membrane became evident. Following gentle fracture of the bony plate, the membrane was elevated.

‡ Hu-Friedy Manufacturing Company Inc., Chicago, IL. 


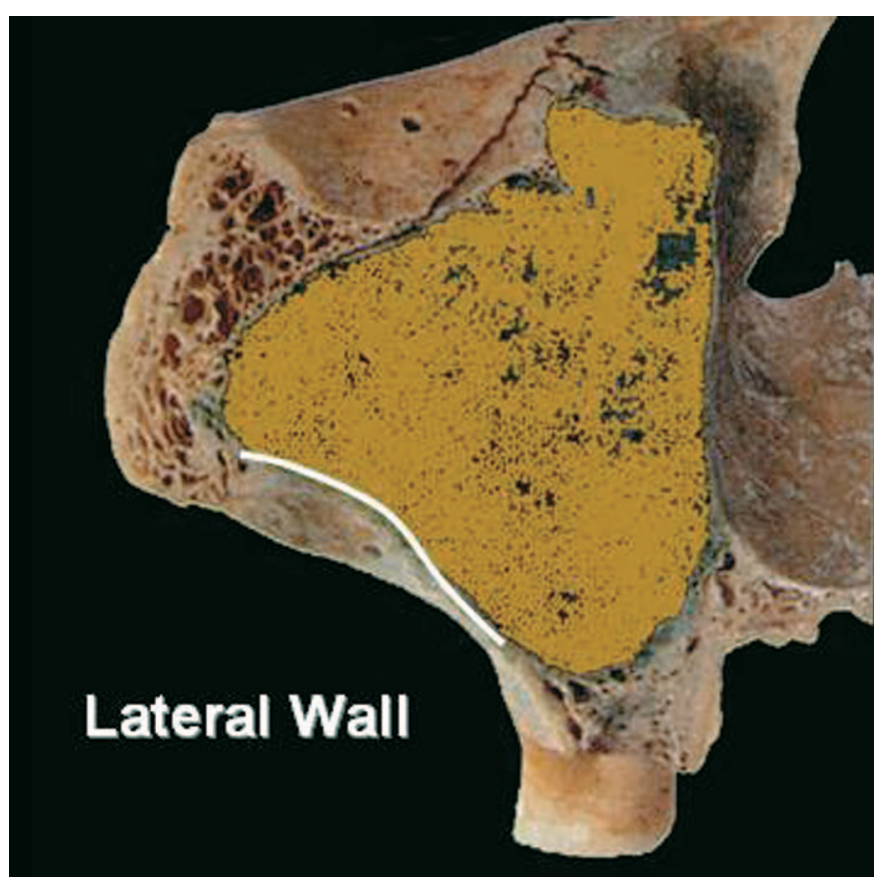

Figure 3.

The thickness of the lateral wall of the maxillary sinus was measured in four locations: mesial, distal, apical, and coronal.

The thickness of the lateral wall of each maxillary sinus was then recorded using a Boley gauge caliper.§ Measurements were recorded to the nearest $0.5 \mathrm{~mm}$ (Fig. 3).

\section{Statistical Analyses}

The data were computerized and the statistical analysis was performed with a software program." Initially, description analysis was performed to display mean, standard deviations, and range for all parameters measured considering the entire population. Then, two-tailed independent $t$ test was carried out to establish possible differences between male and female specimens. Means were considered to be significantly different when $P<0.05$. Multiple regression analysis in a step-up manner was used to test whether AL, MF-CEJ, MF-LC, MF-MD, MF-MF, GH, G-W, G-T, G-V, and T-LW were affected by age and other correlated factors. To evaluate the overall statistical significance of each linear regression the values of $r$, $r^{2}$ were reported. The $95 \%$ probability was used.

\section{RESULTS}

None of the specimens showed the cause of death as contributing to variations of anatomical measurements.

\section{Mental Foramen}

Size. The size of the MF varied considerably both in height and width. However, consistent values of both height and width were noted for the same MF, characterizing the rounded morphology normally noted radiographically. The mean height of the MF was $3.47 \pm$
Table I.

\section{Size and Location of Mental Foramen}

\begin{tabular}{lcc}
\hline Location & Mean Size $(\mathrm{mm})$ & Range $(\mathrm{mm})$ \\
\hline MF-H & $3.47 \pm 0.71$ & $2.5-5.5$ \\
MF-W & $3.59 \pm 0.8$ & $2-5.5$ \\
MF-CEJ & $15.52 \pm 2.37$ & $12-22$ \\
MF-LC & $12 \pm 1.67$ & $9-15$ \\
MF-MD & $27.61 \pm 2.29$ & $22-31$ \\
MF-MF & $55.23 \pm 5.34$ & $46-62$ \\
\hline
\end{tabular}

$0.71 \mathrm{~mm}$ (range: 2.5 to $5.5 \mathrm{~mm}$ ) and the mean width was $3.59 \pm 0.8 \mathrm{~mm}$ (range: 2 to $5.5 \mathrm{~mm}$ ) (Table 1 ).

Location. The most common location of the MF in relation to neighboring teeth was in an apical position between the first and second mandibular premolars (58\%), followed by immediately apical to the second mandibular premolar (42\%). The mean distance from the most coronal aspect of the MF to the most apical aspect of the CEJ of the tooth immediately superior to the $M F$ was $15.52 \pm 2.37 \mathrm{~mm}$ (range: 12 to $22 \mathrm{~mm}$ ). The mean distance from the most apical portion of the MF to the most apical portion of the lower cortex of the mandible immediately inferior to the MF observed was $12.0 \pm 1.67 \mathrm{~mm}$ (range: 9 to $15 \mathrm{~mm}$ ). Measurements of the most mesial aspect of each MF to the midline of the symphysis revealed a mean distance of $27.61 \pm$ $2.29 \mathrm{~mm}$ (range: 22 to $31 \mathrm{~mm}$ ). The mean length of a straight line measured from the most mesial aspect of each MF in relation to the contralateral MF was 55.23 $\pm 5.34 \mathrm{~mm}$ (range: 46 to $62 \mathrm{~mm}$ ) (Table 1 ).

\section{Symphysis Onlay Grafts}

Following harvesting, onlay symphysis grafts varied considerably in terms of length of the graft obtained after osteotomy (11 to $20 \mathrm{~mm}$ ). This variation was significantly correlated with the distances from the most mesial aspect of the MF to the midline of the symphysis and to the mesial aspect of the contralateral MF. The mean length of the blocks obtained was $14.5 \pm 3 \mathrm{~mm}$. The height and thickness measurements of the blocks were more consistent. The mean height observed was $9.45 \pm$ $1.08 \mathrm{~mm}$ (range: 8 to $12 \mathrm{~mm}$ ), width $14.5 \pm 3.0 \mathrm{~mm}$ (range: 11 to $20 \mathrm{~mm}$ ), and the mean thickness was $6.15 \pm 1.04 \mathrm{~mm}$ (range: 4 to $8 \mathrm{~mm}$ ). These measurements allowed calculation of the volume of these blocks, and the mean volume was $857.55 \pm 283.97 \mathrm{~mm}^{3}$ (range: 352 to $1,200 \mathrm{~mm}^{3}$ ) (Table 2). These blocks showed more

$\S$ Yates E Bird Dental Lab Products Inc., Chicago, IL.

\| Statistica, StatSoft Inc., Tulsa, OK. 
Table 2.

\section{Symphysis Onlay Grafts}

\begin{tabular}{lcc}
\hline Measurement & Mean Size $(\mathrm{mm})$ & Range $(\mathrm{mm})$ \\
\hline Height & $9.45 \pm 1.08$ & $8-12$ \\
Width & $14.5 \pm 3.00$ & $11-20$ \\
Thickness & $6.15 \pm 1.04$ & $4-8$ \\
Volume $\left(\mathrm{mm}^{3}\right)$ & $857.55 \pm 283.97$ & $352-1,200$ \\
\hline
\end{tabular}

cortical than cancellous bone. The mean percentage of cortical bone noted was $64.5 \% \pm 16.37 \%$ (range: $40 \%$ to $100 \%$ ) and the mean percentage of cancellous bone was $35.5 \% \pm 16.38 \%$ (range: $10 \%$ to $60 \%$ ).

\section{Anterior Loops}

A high incidence of anterior loops of the IAN was noted in the analyzed specimens ( $88 \%$ versus $12 \%$ without loops), and this anatomic feature was frequently present bilaterally $(76.2 \%$ versus $23.8 \%$ unilateral). A wide range was noted regarding the extent of the anterior loop (1 to $11 \mathrm{~mm}$ ) with a mean length of $4.13 \pm 2.04 \mathrm{~mm}$.

\section{Maxillary Sinuses}

After osteotomy and elevation of the sinus membrane, the mean thickness of the lateral wall of the maxillary sinuses was $0.91 \pm 0.43$ (range: 0.5 to $2 \mathrm{~mm}$ ), which was consistent throughout the edges of the analyzed windows.

\section{Multiple Regression Analysis}

Results from statistical regression analysis demonstrated that no correlations among age and mesial extent of the AL $\left(r=0.12, r^{2}=0.015, P=0.58\right)$, MF-CEJ $(r=0.35$, $\left.\mathrm{r}^{2}=0.12, P=0.13\right)$, MF-LC $\left(\mathrm{r}=0.09, \mathrm{r}^{2}=0.009, P=\right.$ 0.67), MF-MF $\left(\mathrm{r}=0.22, \mathrm{r}^{2}=0.05, P=0.32\right)$, G-V $(\mathrm{r}=$ $\left.0.12, \mathrm{r}^{2}=0.01, P=0.59\right)$, and T-LW $\left(\mathrm{r}=0.31, \mathrm{r}^{2}=0.1\right.$, $P=0.15$ ) were found. A close, but not statistically significant, correlation was found between MF-MF and volume of graft removed $\left(\mathrm{r}=0.42, \mathrm{r}^{2}=0.18, P=0.06\right)$. Results also demonstrated no statistically significant differences between genders for all parameters except extent of AL (males, 2.88 versus females, $4.70 ; P<0.02$ ) and T-LW (males, 1.18 versus females, $0.75, P<0.02$ ) (Table 3 ).

\section{DISCUSSION}

Implant placement requires presurgical treatment planning and in-depth knowledge of oral anatomy in order to avoid damage to surrounding anatomical structures. ${ }^{4}$ Frequently, placement of dental implants requires horizontal and/or vertical augmentation of the alveolar ridge in order to facilitate adequate placement of the fixtures. These procedures can also result in body dam-
Table 3.

Multiple Regression Analyses (mean \pm SD)

\begin{tabular}{|c|c|c|c|}
\hline & $\begin{array}{l}\text { Males } \\
(\mathrm{N}=9)\end{array}$ & $\begin{array}{l}\text { Females } \\
(\mathrm{N}=13)\end{array}$ & $P$ Value \\
\hline Age (years) & $78.2 \pm 9.03$ & $79.7 \pm 13.12$ & 0.29 \\
\hline $\mathrm{MF}-\mathrm{H}(\mathrm{mm})$ & $3.61 \pm 0.82$ & $3.37 \pm 0.64$ & 0.46 \\
\hline MF-W (mm) & $3.55 \pm 0.68$ & $3.62 \pm 0.91$ & 0.84 \\
\hline $\mathrm{AL}(\mathrm{mm})$ & $2.88 \pm 1.08$ & $4.70 \pm 1.97$ & 0.02 \\
\hline MF-CEJ (mm) & $16.68 \pm 2.68$ & $14.72 \pm 1.48$ & 0.06 \\
\hline MF-LC (mm) & $12.0 \pm 1.58$ & $12.0 \pm 1.81$ & 1.0 \\
\hline MF-MF (mm) & $55.77 \pm 5.02$ & $54.83 \pm 4.19$ & 0.64 \\
\hline $\mathrm{G}-\mathrm{V}\left(\mathrm{mm}^{3}\right)$ & $788.5 \pm 318.9$ & $903.58 \pm 263.82$ & 0.38 \\
\hline T-LW (mm) & $1.18 \pm 0.46$ & $0.75 \pm 0.33$ & 0.02 \\
\hline
\end{tabular}

age if the surrounding anatomical structures are not respected and consequently injured. ${ }^{5-8}$

Paresthesia is a complication commonly related to injury of the inferior alveolar nerve (IAN) during placement of implants in the posterior mandible. Paresthesia is a condition that involves perverted sensations of pain, touch, or temperature and is considered to be the most significant damage caused by implant placement since this condition can become permanent. ${ }^{9,10}$ Common techniques used to avoid damage to the IAN include measurement of the distance from the alveolar crest to the most coronal aspect of the mandibular canal and estimation of certain depth for the osteotomy that would avoid injury to this neurovascular bundle based on periapical and/or panoramic radiographs. ${ }^{11}$ However, this radiographic assessment has been shown to provide images with a significant degree of distortion, increasing the risk of complications. ${ }^{12,13}$ More precise imaging techniques such as computerized tomography are available; however, they are not the standard of care and do expose the patient to relatively high levels of radiation. ${ }^{14}$ Another technique commonly used is the infiltration of local anesthetic agents instead of blocking the IAN before surgery. ${ }^{15}$ Blockage of the IAN eliminates all somatosensory perception of the mandible, mandibular teeth, floor of the mouth, ipsilateral tongue, and buccal soft tissue. As a consequence, the patient is not able to sense when the IAN is in danger of being injured. ${ }^{16}$ Local infiltration of anesthetic cannot be the only tool used to avoid nerve damage since variations of sensory perception exist among different individuals. ${ }^{17-20}$

A technique of lateralization of the IAN was developed for cases where the distance from the alveolar crest to the most coronal aspect of the mandibular crest does 
not allow placement of fixtures of adequate length. ${ }^{21,22}$ A high incidence of transient or permanent nerve damage $(54.7 \%)$ has been reported following utilization of this technique. ${ }^{23}$

Another anatomical landmark commonly used during implant treatment planning is the mental foramen. ${ }^{24}$ The $M F$ region is also an area that deserves special attention during implant placement since the IAN exits the mandibular canal through this foramen. ${ }^{25}$ Variation in the position of the MF with respect to the teeth does not seem to be associated with race since various reports have shown that the most common locations are between the apices of mandibular premolar (PM) teeth or below the second mandibular premolar irrespective of race $^{25-36}$ (Table 4). Our findings are in agreement with previous studies that have identified that the MF is most commonly located apically between first and second premolars, followed by apical to the mandibular second premolar. Oguz et al. ${ }^{36}$ attempted to determine the most common location of the MF in Turkish skulls. His findings demonstrated that the mean distances between the $\mathrm{MF}$ and the lower cortex (LC) of the mandible and between the MF and the alveolar crest were $14.45 \mathrm{~mm}$ and $14.12 \mathrm{~mm}$, respectively. ${ }^{36}$

Our study selected the CEJ of the tooth immediately superior to the MF as a landmark since the specimens could have experienced crestal bone loss during life as a result of periodontal diseases. The rationale behind utilization of CEJ instead of the alveolar crest was based on the following: 1) a considerable variation on the position of the alveolar crest was observed in our specimens in a preliminary evaluation, since only dentate cadavers were evaluated; 2) for this reason, the adjacent CEJs were used as supposedly fixed and more constant ref-

\section{Table 4.}

Studies That Have Located the Mental Foramen in Relation to Closest Tooth in Different Ethnic Groups

\begin{tabular}{ll}
\hline Population & \multicolumn{1}{c}{ Results/Studies } \\
\hline Thai & $63 \%$ between $\mathrm{PMs}^{26,27}$ \\
Chinese & $67 \%$ between $\mathrm{PMs}^{29}$ \\
& $60 \%$ below $2 \mathrm{nd} \mathrm{PM}^{32}$ \\
Korean & $60 \%$ between $\mathrm{PMs}^{25}$ \\
Turkish & $62 \%$ below $2 \mathrm{nd} \mathrm{PM}^{36}$ \\
Saudi Arabian & $43 \%$-84\% between PMs \\
& $45 \%$ below $2 \mathrm{nd} \mathrm{PM}^{35}$ \\
Nigerian & $56 \%$ below $2 \mathrm{nd} \mathrm{PM}^{33}$ \\
Caucasian & $60 \%$-70\% between PMs \\
& $60 \%$ below $2 \mathrm{nd} \mathrm{PM}^{34}$ \\
\hline
\end{tabular}

erence points, since using the alveolar crest of a dentate site would not be as accurate as using the alveolar crest of an edentulous site; and 3) we also considered new techniques of immediate implant placement that allow placement of implant fixtures immediately following tooth extraction. Based on these reasons we considered adjacent CEJs as the most accurate and reproducible reference point for measurements.

Future studies using edentulous specimens are needed for comparison with our current findings. It would also be interesting to know the exact time of tooth loss and estimate the rate of progression of alveolar crest resorption by evaluating these distances. Despite the different reference point, measurements comparable to previous studies were detected, since the mean distance between the MF-CEJ was $15.52 \mathrm{~mm}$. The effect of tooth wear and subsequent passive eruption of the teeth used as coronal anatomical landmarks for the position of the MF may also explain the slight difference in our measurements. ${ }^{37}$ The difference between the measurements of MF-LC could be related to a racial variation or migration of the IAN and MF with age since our specimens had a mean age of 79.1 years. Reports have shown that, possibly as a result of bone associated diseases (i.e., osteoporosis), the IAN and the MF in elderly skulls were located more coronally when compared to younger skulls. ${ }^{38-41}$ However, Xie et al. observed that mean MF-LC measurements were also smaller in old edentulous subjects than in young and old dentate subjects, demonstrating that it is possible that not only alveolar bone resorption, but also basal bone atrophy could interfere with the position of the MF. ${ }^{42}$

The presence of an anterior loop (AL) of the IAN is a significant anatomical variation in implant dentistry since nerve injury can occur as a result of inadvertent invasion of this area during implant osteotomy or when block grafts are harvested from the symphysis area. ${ }^{43-45}$ Previous reports have shown a significant variation of the prevalence of these loops. ${ }^{46-49}$ The prevalence seems to range between $28 \%$ to $94 \% .{ }^{46,49}$ Our findings (88\%) are in agreement with the findings of Kieser et al. who reported an overall prevalence of $83 \% .{ }^{48}$ Our specimens showed that symmetry of anterior loops is a common finding, since in $76.2 \%$ of the specimens bilateral loops were found. Previous reports have also shown significant variation of the length of the mesial extension of these loops, ranging from $1.2 \mathrm{~mm}$ to $6.95 \mathrm{~mm} .{ }^{46,48,49}$ Our specimens showed a mean length of $4.13 \mathrm{~mm}$. These measurements seemed to be constant, without significant variations among the specimens. Previous reports have also compared clinical and radiographic assessments of the presence and extension of the AL and showed that radiographic assessment tends to underestimate the mesial extent of the loop and frequently hides the loop due to overimposition of other radiopaque structures, emphasizing the need of clinical assessment. ${ }^{46,49,50}$ 
Augmentation of atrophic alveolar ridges with onlay grafts is frequently necessary to allow proper implant placement. ${ }^{51}$ The symphyseal area is a common source for block grafts due to ample supply of donor material, the proximity to the recipient site, and the ease of access when compared to other intraoral donor areas, such as mandibular ramuses. ${ }^{52}$ The amount of augmentation is directly dependent on the size of the harvested graft when no additional grafting materials are used. These grafts have also shown to resorb an average $20 \%$ to $25 \%$ during the healing process. ${ }^{53}$ The average size of the grafts obtained in our study was $14.5 \times 9.45 \times 6.15 \mathrm{~mm}$ with a mean volume of $857.55 \mathrm{~mm}^{3}$. These findings are in agreement with Montazem et al. who reported average graft volume of $4.77 \mathrm{~mL}$, and average block size of $20.9 \times 9.9 \times 6.9 \mathrm{~mm}^{.}{ }^{54}$ Gungormus et al. found in a similar study that the average size of symphyseal block grafts was $45.36 \times 10.31 \times 9.63 \mathrm{~mm} .{ }^{55}$ The differences noted in these findings are related to the technique used for block harvesting. While Montazem et al. ${ }^{54}$ harvested two blocks from the symphysis by respecting the midline, Gungormus et al. harvested only one block, including the midline of the symphysis in the block. For this reason, our findings are in closer agreement with the Montazem et al. study ${ }^{54}$ (Table 2).

The lateral approach for maxillary sinus elevation described by Tatum et al. is commonly used to increase bone height prior to placement of implants in the posterior maxilla. ${ }^{56}$ Autografts, allografts, xenografts, and alloplasts are normally used to achieve this goal. ${ }^{57}$ When an osteotomy is performed to gain access to maxillary sinuses through the lateral wall, variations on the thickness of this wall may increase the chances of perforating the Schneiderean membrane. Our study expected to find significant differences among individuals and among different locations, especially on the posterior portion of this wall, since this area is in close proximity with the zygomatic bone and arch. However, no significant differences were found in our sample. The mean thickness of the lateral was found to be $0.91 \mathrm{~mm}$ $(0.5$ to $2.0 \mathrm{~mm})$. It is possible that thicker lateral walls could be found in a younger sample, possibly due to less pneumatization of the maxillary sinus. Future studies are needed to confirm this hypothesis.

Within the limits of this study, it can be concluded that implant-related anatomy needs to be carefully evaluated prior to treatment. Profound knowledge of this anatomy will certainly decrease the chances of complications.

\section{ACKNOWLEDGMENT}

This work was partially supported by the University of Michigan Periodontal Graduate Student Research Fund.

\section{REFERENCES}

1. Chaushu G, Taicher S, Halamish-Shani T, Givol N. Medicolegal aspects of altered sensation following implant placement in the mandible. Int $J$ Oral Maxillofac Implants 2002; 17:413-415.

2. Hunt DR, Jovanovic SA. Autogenous bone harvesting: A chin graft technique for particulate and monocortical bone blocks. Int J Periodontics Restorative Dent 1999;19:165-173.

3. Tatum H Jr. Maxillary and sinus implant reconstructions. Dent Clin North Am 1986;30:207-229.

4. Obradovic O, Todorovic L, Vitanovic V. Anatomical considerations relevant to implant procedures in the mandible. Bull Group Int Rech Sci Stomatol Odontol 1995;38:39-44.

5. Garg AK, Morales MJ. Lateralization of the inferior alveolar nerve with simultaneous implant placement: Surgical techniques. Pract Periodontics Aesthet Dent 1998;10:1197-1204.

6. Peleg M, Mazor Z, Chaushu G, Garg AK. Lateralization of the inferior alveolar nerve with simultaneous implant placement: A modified technique. Int J Oral Maxillofac Implants 2002;17:101-106.

7. Takeuchi T, Furusawa K, Hirose I. Mechanism of transient mental nerve paraesthesia in sagittal split mandibular ramus osteotomy. Br J Oral Maxillofac Surg 1994;32: 105-108.

8. Bavitz JB, Harn SD, Hansen CA, Lang M. An anatomical study of mental neurovascular bundle-implant relationships. Int J Oral Maxillofac Implants 1993;8:563-567.

9. Morse DR. Endodontic-related inferior alveolar nerve and mental foramen paresthesia. Compend Contin Educ Dent 1997;18:963-968, 970-973, 976-978 passim; quiz 998.

10. Givol N, Taicher S, Halamish-Shani T, Chaushu G. Risk management aspects of implant dentistry. Int $J$ Oral Maxillofac Implants 2002;17:258-262.

11. de Freitas V, Madeira MC, Toledo Filho JL, Chagas CF. Absence of the mental foramen in dry human mandibles. Acta Anat 1979;104:353-355.

12. Grondahl K, Ekestubbe A, Grondahl HG, Johnsson T. Reliability of hypocycloidal tomography for the evaluation of the distance from the alveolar crest to the mandibular canal. Dentomaxillofac Radiol 1991;20:200-204.

13. Xie Q, Soikkonen K, Wolf J, Mattila K, Gong M, Ainamo A. Effect of head positioning in panoramic radiography on vertical measurements: An in vitro study. Dentomaxillofac Radiol 1996;25:61-66.

14. Bou Serhal C, Jacobs R, Flygare L, Quirynen M, van Steenberghe D. Perioperative validation of localisation of the mental foramen. Dentomaxillofac Radiol 2002;31: 39-43.

15. Biggs JT, Sabala C. Variations in the size and location of the mental foramen. J Okla Dent Assoc 1995;85:18-20.

16. Heller AA, Shankland WE 2nd. Alternative to the inferior alveolar nerve block anesthesia when placing mandibular dental implants posterior to the mental foramen. J Oral Implantol 2001;27:127-133.

17. Jaaskelainen SK. A new technique for recording sensory conduction velocity of the inferior alveolar nerve. Muscle Nerve 1999;22:455-459.

18. Deeb GR, Dierks E, So YT. Sensory nerve conduction study of the mental nerve. Muscle Nerve 2000;23:1121-1124.

19. Jaaskelainen SK, Teerijoki-Oksa T, Forssell K, Vahatalo $\mathrm{K}$, Peltola JK, Forssell H. Intraoperative monitoring of the inferior alveolar nerve during mandibular sagittal-split osteotomy. Muscle Nerve 2000;23:368-375.

20. Essick GK, Whitsel BL, Dolan PJ, Kelly DG. Effects of traverse length on human perioral directional sensitivity. J Neurol Sci 1989;93:175-190.

21. Rosenquist B. Fixture placement posterior to the mental foramen with transpositioning of the inferior alveolar nerve. Int J Oral Maxillofac Implants 1992;7:45-50. 
22. Smiler DG. Repositioning the inferior alveolar nerve for placement of endosseous implants: Technical note. Int J Oral Maxillofac Implants 1993;8:145-150.

23. Kan JY, Lozada JL, Goodacre CJ, Davis WH, Hanisch O. Endosseous implant placement in conjunction with inferior alveolar nerve transposition: An evaluation of neurosensory disturbance. Int J Oral Maxillofac Implants 1997;12:463-471.

24. Packota GV, Hoover JN, Neufeld BD. A study of the height of intact alveolar bone on panoramic radiographs of adult patients. J Prosthet Dent 1988;60:504-509.

25. Chung MS, Kim HJ, Kang HS, Chung IH. Locational relationship of the supraorbital notch or foramen and infraorbital and mental foramina in Koreans. Acta Anat 1995; 154:162-166.

26. Srisopark SS. Location of mental foramen in man. J Dent Assoc Thai 1973;23:241-256.

27. Boonpiruk N. Location of mental foramen in Thai skulls. $J$ Dent Assoc Thai 1975;25:295-302.

28. Fishel D, Buchner A, Hershkowith A, Kaffe I. Roentgenologic study of the mental foramen. Oral Surg Oral Med Oral Pathol 1976;41:682-686.

29. Kuo YS, Wu SJ, Shiau JY. Orthopantomographic study on the location of the mental foramen and mandibular canal in Chinese. Taiwan Yi Xue Hui Za Zhi 1987;86:81-86.

30. al-Khateeb TL, Odukoya O, el-Hadidy MA. Panoramic radiographic study of mental foramen locations in Saudi Arabians. Afr Dent J 1994;8:16-19.

31. Moiseiwitsch JR. Position of the mental foramen in a North American, white population. Oral Surg Oral Med Oral Pathol Oral Radiol Endod 1998;85:457-460.

32. Wang TM, Shih C, Liu JC, Kuo KJ. A clinical and anatomical study of the location of the mental foramen in adult Chinese mandibles. Acta Anat 1986;126:29-33.

33. Kekere-Ekun TA. Antero-posterior location of the mental foramen in Nigerians. Afr Dent $J$ 1989;3:2-8.

34. Phillips JL, Weller RN, Kulild JC. The mental foramen: 1. Size, orientation, and positional relationship to the mandibular second premolar. J Endod 1990;16:221-223.

35. al Jasser NM, Nwoku AL. Radiographic study of the mental foramen in a selected Saudi population. Dentomaxillofac Radiol 1998;27:341-343.

36. Oguz O, Bozkir MG. Evaluation of location of mandibular and mental foramina in dry, young, adult human male, dentulous mandibles. West Indian Med J 2002;51:14-16.

37. Green RM, Darvell BW. Tooth wear and the position of the mental foramen. Am J Phys Anthropol 1988;77:69-75.

38. Hirai T, Ishijima T, Hashikawa Y, Yajima T. Osteoporosis and reduction of residual ridge in edentulous patients. $J$ Prosthet Dent 1993;69:49-56.

39. Soikkonen K, Wolf J, Ainamo A, Xie Q. Changes in the position of the mental foramen as a result of alveolar atrophy. J Oral Rehabil 1995;22:831-833.

40. Gershenson A, Nathan H, Luchansky E. Mental foramen and mental nerve: Changes with age. Acta Anat 1986;126: 21-28.

41. Karaagaclioglu L, Ozkan P. Changes in mandibular ridge height in relation to aging and length of edentulism period. Int J Prosthodont 1994;7:368-371.
42. Xie Q, Wolf J, Soikkonen K, Ainamo A. Height of mandibular basal bone in dentate and edentulous subjects. Acta Odontol Scand 1996;54:379-383.

43. Santini A, Land M. A comparison of the position of the mental foramen in Chinese and British mandibles. Acta Anat 1990;137:208-212.

44. Dharmar S. Locating the mandibular canal in panoramic radiographs. Int J Oral Maxillofac Implants 1997;12:113-117.

45. Pogrel MA, Smith R, Ahani R. Innervation of the mandibular incisors by the mental nerve. J Oral Maxillofac Surg 1997;55:961-963.

46. Arzouman MJ, Otis L, Kipnis V, Levine D. Observations of the anterior loop of the inferior alveolar canal. Int J Oral Maxillofac Implants 1993;8:295-300.

47. Jacobs R, Mraiwa $N$, vanSteenberghe D, Gijbels $F$, Quirynen M. Appearance, location, course, and morphology of the mandibular incisive canal: An assessment on spiral CT scan. Dentomaxillofac Radiol 2002;31:322-327.

48. Kieser J, Kuzmanovic D, Payne A, Dennison J, Herbison P. Patterns of emergence of the human mental nerve. Arch Oral Biol 2002;47:743-747.

49. Mardinger O, Chaushu G, Arensburg B, Taicher S, Kaffe I. Anterior loop of the mental canal: An anatomical-radiologic study. Implant Dent 2000;9:120-125.

50. Obradovic O, Todorovic L, Pesic V, Pejkovic B, Vitanovic V. Morphometric analysis of mandibular canal: Clinical aspects. Bull Group Int Rech Sci Stomatol Odontol 1993; 36:109-113.

51. Moloney F, Stoelinga PJ, Tideman H, de Koomen HA. Recent developments in interpositional bone-grafting of the atrophic mandible. J Maxillofac Surg 1985;13:14-23.

52. Stoelinga PJ, Blijdorp PA, Ross RR, De Koomen HA, Huybers TJ. Augmentation of the atrophic mandible with interposed bone grafts and particulate hydroxylapatite. J Oral Maxillofac Surg 1986;44:353-360.

53. Misch CM. Comparison of intraoral donor sites for onlay grafting prior to implant placement. Int J Oral Maxillofac Implants 1997;12:767-776.

54. Montazem A, Valauri DV, St-Hilaire H, Buchbinder D. The mandibular symphysis as a donor site in maxillofacial bone grafting: A quantitative anatomic study. J Oral Maxillofac Surg 2000;58:1368-1371.

55. Gungormus M, Yilmaz AB, Ertas U, Akgul HM, Yavuz MS, Harorli A. Evaluation of the mandible as an alternative autogenous bone source for oral and maxillofacial reconstruction. J Int Med Res 2002;30:260-264.

56. Tatum OH Jr, Lebowitz MS, Tatum CA, Borgner RA. Sinus augmentation. Rationale, development, long-term results. NY State Dent J 1993;59:43-48.

57. Smiler DG, Johnson PW, Lozada JL, et al. Sinus lift grafts and endosseous implants. Treatment of the atrophic posterior maxilla. Dent Clin North Am 1992;36:151-188.

Correspondence: Dr. Hom-Lay Wang, Graduate Periodontics, University of Michigan, School of Dentistry, 1011 N. University Ave., Ann Arbor, MI 48109-1078. Fax: 734/763-5503; e-mail: homlay@umich.edu.

Accepted for publication December 1, 2003. 